\title{
Studi Eksperimen Pengaruh Variasi Besaran Sudut Buang Dan Sudut Bebas Menggunakan Pahat Tepi Rata Dengan Material Pahat HSS Terhadap Kekasaran Permukaan Pada Proses Pembubutan Benda Kerja Dengan Material Benda Kerja St 41
}

\author{
Gerry Patriadicka*, Erwansyah Iskak, Juanda \\ Prodi Teknik Mesin dan Manufaktur. Polman Babel. Kawasan Industri Air Kantung. Sungailiat, \\ Bangka Belitung \\ *gerrypd28@gmail.com
}

\begin{abstract}
A good level of surface roughness as one of the benchmarks for turning the work piece was said to be of high quality. As a cutting tool, lathe chisels need free angles and exhaust angles according to the desired specifications. This study aims to determine the effect of variations in the size of the tool angle and how much free angle and exhaust angle are best used on the surface roughness of St 41 steel. The study was conducted using a lathe brand Bemato series 44376 with process parameters consisting of a spindle speed of $280 \mathrm{~m} / \mathrm{min}$, the in feed depth is 0.8 $\mathrm{mm}$, and the in feed speed is $0.040 \mathrm{~mm} / \mathrm{rev}$. The research method used is an experimental method and the results of the turning process are measured the level of surface roughness using a surface roughness tester. Based on the results of the specimen measurements, it is found that there are differences in surface roughness produced by variations in the free angle $(\alpha)$ and exhaust angle $(\beta)$. As for the lowest roughness value of the whole specimen turning process is in the turning process with variations in angle $6^{\circ}$ and angle $10^{\circ}$ with a surface roughness value (Ra) of 2,555 m.
\end{abstract}

Keywords : Surface roughness, Surface roughness tester, Lathe

\section{PENDAHULUAN}

Pada perkembangan zaman saat ini ditambah memasuki era digital 4.0 tak heran jika persaingan industri manufaktur sangat meningkat cepat. Hal ini terjadi atas perkembangan ilmu dan teknologi yang semakin maju. Proses produksi pembuatan suatu produk manufaktur memerlukan proses permesinan untuk menghasilkan suatu produk jadi, salah satunya adalah proses pengerjaan benda kerja dimesin bubut atau yang biasa disebut proses pembubutan. Tujuan dari proses pembubutan yaitu untuk mendapatkan produk yang berkualitas sesuai dengan karakteristik dan spesifikasi yang diinginkan, maka diperlukan upaya untuk menekan dan meminimalisir kesalahankesalahan yang mungkin akan terjadi pada saat proses pembubutan. Proses permesinan dalam membuat suatu produk pasti meninggalkan guratan-guratan yang akan menimbulkan kekasaran pada permukaan benda kerja. Kekasaran permukaan pada hakekatnya merupakan ketidakteraturan konfigurasi permukaan yang bisa berupa guratan pada permukaan (Taufiq Rochim, 2001). Beberapa parameter permesinan yang mempengaruhi kualitas kekasaran permukaan adalah jenis material pahat, jenis material benda kerja, besaran sudut potong, kecepatan putar dari spindel, gerak pemakanan benda kerja atau feeding, dan kedalaman potong. Semakin besar kedalaman potong yang digunakan akan menyebabkan pembentukan tatal yang tersambung atau kontinu dan sebaliknya kedalaman potong yang semakin rendah akan menghasilkan tatal yang terputus-putus atau terpisah (Raul, Widiyanti, \& Poppy, 2016). 
Salah satu faktor terpenting yang menentukan keberhasilan proses pembubutan adalah pahat sebagai alat potongnya. Oleh karena itu, sebelum melakukan proses pembubutan harus memperhatikan geometri pahat bubutnya. Untuk dapat memotong dengan baik, pahat bubut perlu adanya sudut baji, sudut potong, sudut bebas, dan sudut buang sesuai ketentuan dan spesifikasi yang diinginkan. Sudut potong pahat berpengaruh terhadap nilai kekasaran permukaan, semakin kecil sudut potong utama pahat $(\mathrm{Kr})$ maka gaya potong akan semakin lebar dan tebal geram juga akan semakin besar, semakin besar tebal geram maka akan mempengaruhi tingkat kekasaran yang lebih besar juga (A. Firstamarsyah \& A. Sakti, 2019). Pahat yang digunakan pun harus memiliki sifat Hot Hardness yaitu kekerasan dan kekuatan pahat tetap ada pada temperatur tinggi, sehingga nantinya pada proses pembubutan yang sudah dilakukan dapat menghasilkan produk yang berkualitas baik serta ekonomis. Pada penelitian ini penulis menggunakan pahat dengan material HSS (High Speed Steel). Pahat dari HSS biasanya dipilih jika ada proses pembubutan sering terjadi beban kejut, atau pembubutan yang sering dilakukan interupsi atau terputus-putus (A. Hendrawan, 2015). Oleh karena itu dalam penyusunan proposal ini penulis mengambil judul "Studi Eksperimen Pengaruh Variasi Besaran Sudut Buang dan Sudut Bebas Menggunakan Pahat Tepi Rata Dengan Material Pahat HSS Terhadap Kekasaran Permukaan Pada Proses Pembubutan Benda Kerja Dengan Material Benda Kerja St 41”.

\section{METODE PENELITIAN}

Hasil observasi dan pengumpulan data dari berbagai sumber, kemudian dilakukan eksperimen yaitu dengan melakukan proses pembubutan benda kerja menggunakan mesin bubut konvensional dan kemudian hasil dari pembubutan benda kerja dilakukan proses pengujian kekasaran permukaan menggunakan alat uji surface roughness tester.

\subsection{Objek Penelitian}

Objek penelitian yaitu baja st 41 berdiameter $25 \mathrm{~mm}$ dan panjang $100 \mathrm{~mm}$ sebanyak 9 spesimen.

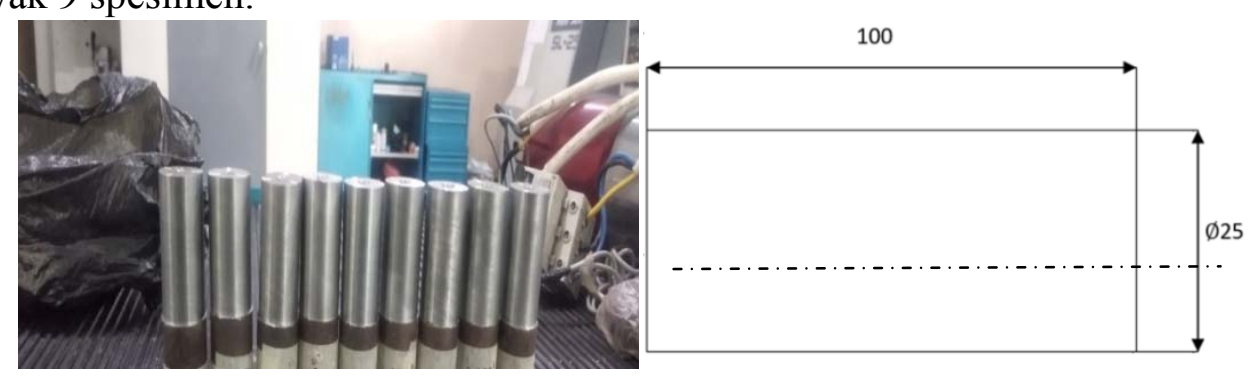

Gambar 1. Bentuk dan dimensi spesimen uji

\subsection{Tahapan Penelitian}

Tahapan Penelitian yang dilakukan mengikuti diagram alir yang ditunjukkan pada gambar 2. 


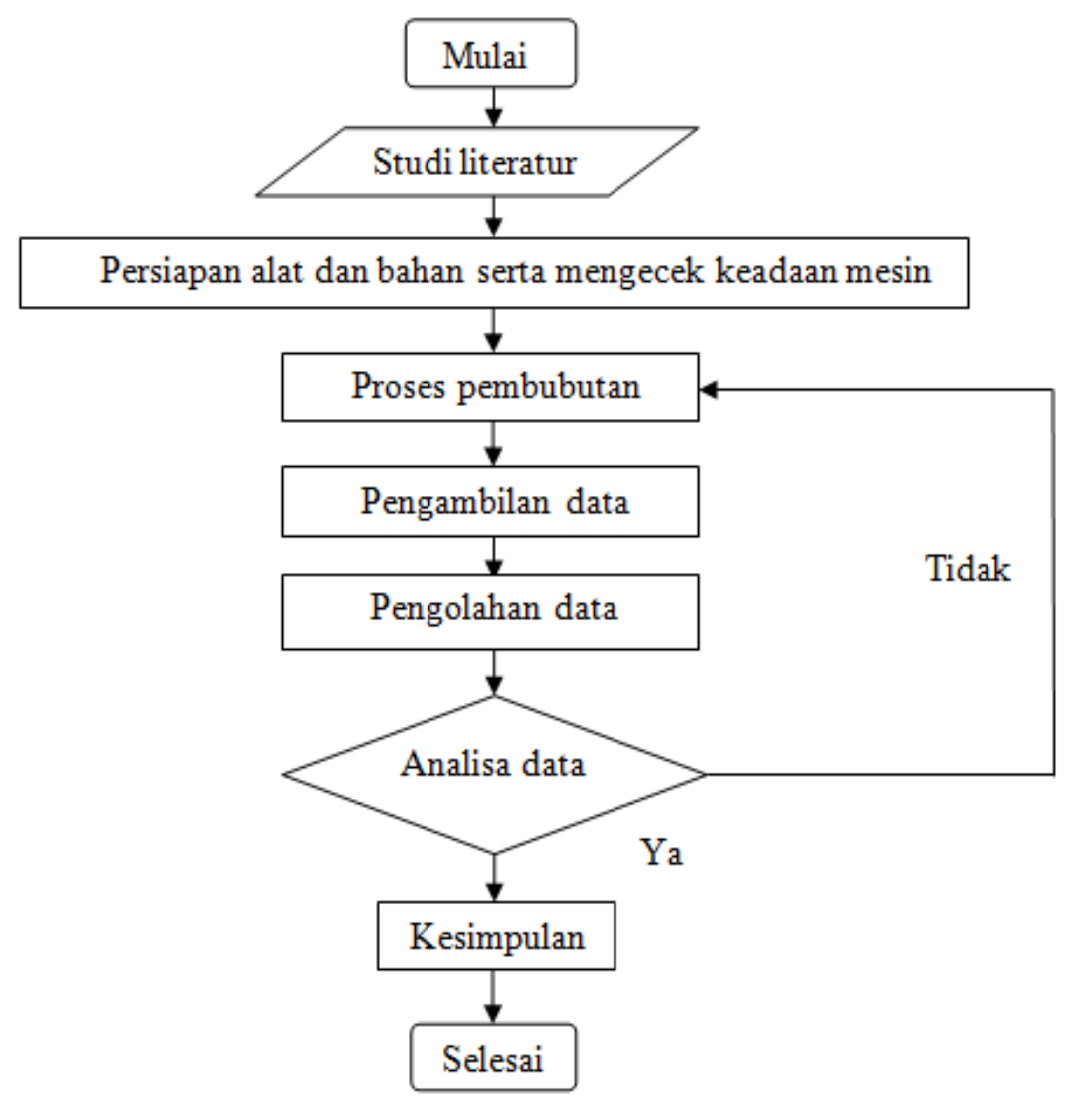

Gambar 2. Diagram penelitian

\subsection{Alat dan Bahan}

1. Mesin bubut horizontal merk bemato dengan serie/type 44376 seperti pada gambar 3 .

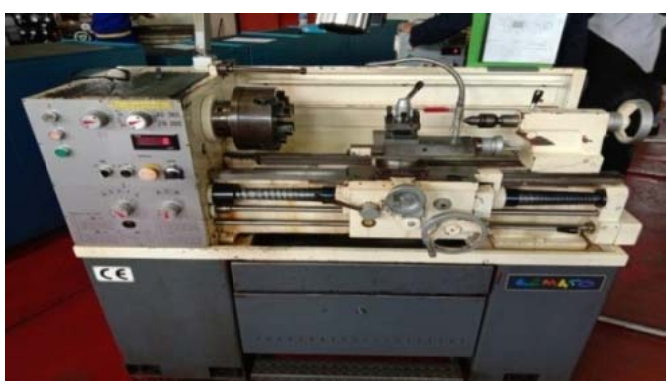

Gambar 3. Mesin bubut

2. Pahat bubut tepi rata dengan material pahat HSS $1 / 2 \times 6$ Bohler seperti pada gambar 4 .

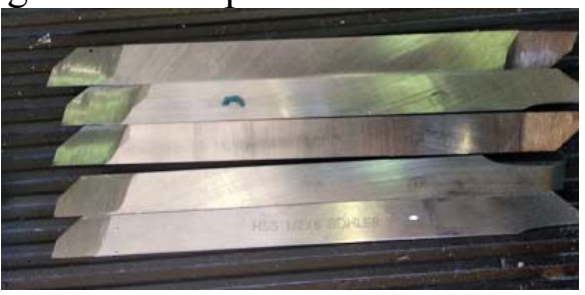

Gambar 4. Pahat bubut 
3. Alat uji kekasaran permukaan yaitu surface roughness tester seperti pada gambar 5.

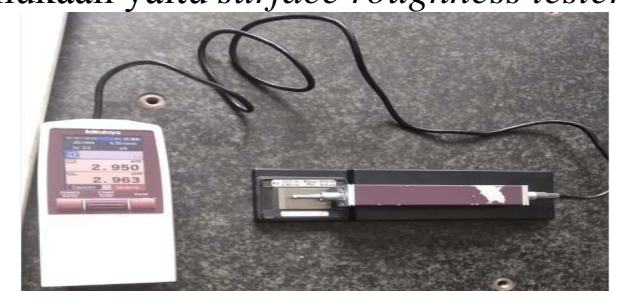

Gambar 5. Surface roughness tester

4. Bahan spesimen uji yaitu baja st 41 sebanyak 9 spesimen seperti pada gambar 6 .

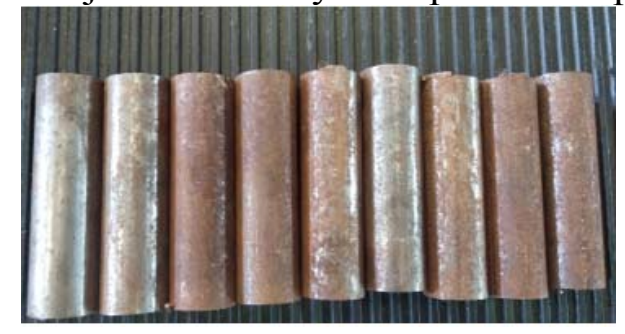

Gambar 6. Bahan spesimen uji

\subsection{Langkah-Langkah Penelitian}

Tahapan pada penelitian ini berurutan dimulai dengan persiapan mesin bubut konvensional, pahat bubut tepi rata (HSS), baja st 41 sebanyak 9 spesimen, dan alat uji kekasaran surface roughness tester. Semua alat dan bahan yang berhubungan dengan penelitian ini akan disiapkan dengan sebaik mungkin supaya proses penelitian ini terarah. Pada penelitian ini, besaran sudut bebas $(\alpha)$ yang digunakan yaitu $6^{\circ}, 7^{\circ}, 8^{\circ}$. Sedangkan besaran sudut buang $(\beta)$ yang digunakan yaitu $10^{\circ}, 12^{\circ}, 14^{\circ}$ dan kemudian akan divariasikan. Sebelum melakukan proses pembubutan, tiap spesimen diberi kode atau nomor terlebih dahulu agar mempermudah pada saat proses pengujian kekasaran permukaan. Adapun rincian sampel spesimen sebagai berikut.

a. Spesimen 1, dilakukan proses pembubutan dengan besaran sudut buang $10^{\circ}$ dan sudut bebas $6^{\circ}$.

b. Spesimen 2, dilakukan proses pembubutan dengan besaran sudut buang $12^{\circ}$ dan sudut bebas $6^{\circ}$.

c. Spesimen 3 , dilakukan proses pembubutan dengan besaran sudut buang $14^{\circ}$ dan sudut bebas $6^{\circ}$.

d. Spesimen 4, dilakukan proses pembubutan dengan besaran sudut buang $10^{\circ}$ dan sudut bebas $7^{\circ}$.

e. Spesimen 5 , dilakukan proses pembubutan dengan besaran sudut buang $12^{\circ}$ dan sudut bebas $7^{\circ}$.

f. Spesimen 6 , dilakukan proses pembubutan dengan besaran sudut buang $14^{\circ}$ dan sudut bebas $7^{\circ}$.

g. Spesimen 7 , dilakukan proses pembubutan dengan besaran sudut buang $10^{\circ}$ dan sudut bebas $8^{\circ}$.

h. Spesimen 8 , dilakukan proses pembubutan dengan besaran sudut buang $12^{\circ}$ dan sudut bebas $8^{\circ}$.

i. Spesimen 9 , dilakukan proses pembubutan dengan besaran sudut buang $14^{\circ}$ dan sudut bebas $8^{\circ}$. 
Setelah persiapan penelitian selesai, maka akan dilanjutkan dengan penentuan parameter proses seperti kecepatan spindel 280 putaran/menit, kedalaman pemotongan $0,8 \mathrm{~mm}$, dan kecepatan pemakanan $0,040 \mathrm{~mm} /$ putaran seperti yang ditunjukkan pada tabel 1 .

Tabel 1. Parameter proses pembubutan spesimen

\begin{tabular}{|c|c|c|c|c|c|}
\hline \multirow{2}{*}{$\begin{array}{l}\text { Nomor } \\
\text { spesimen }\end{array}$} & \multicolumn{2}{|c|}{ Sudut $\left(^{\circ}\right)$} & \multirow{2}{*}{$\begin{array}{l}\text { Kecepatan spindel } \\
\text { (put/menit) }\end{array}$} & \multirow{2}{*}{$\begin{array}{l}\text { Kedalaman } \\
\text { pemotongan } \\
(\mathrm{mm})\end{array}$} & \multirow{2}{*}{$\begin{array}{c}\text { Kecepatan } \\
\text { Pemakanan } \\
\text { (mm/put) }\end{array}$} \\
\hline & $\begin{array}{c}\text { Bebas } \\
(\alpha)\end{array}$ & $\begin{array}{c}\text { Buang } \\
(\beta)\end{array}$ & & & \\
\hline 1 & 6 & 10 & \multirow{9}{*}{280} & \multirow{9}{*}{0,8} & \multirow{9}{*}{0,040} \\
\hline 2 & 6 & 12 & & & \\
\hline 3 & 6 & 14 & & & \\
\hline 4 & 7 & 10 & & & \\
\hline 5 & 7 & 12 & & & \\
\hline 6 & 7 & 14 & & & \\
\hline 7 & 8 & 10 & & & \\
\hline 8 & 8 & 12 & & & \\
\hline 9 & 8 & 14 & & & \\
\hline
\end{tabular}

Setelah dilakukan proses pembubutan, langkah selanjutnya yaitu melakukan proses uji kekasaran permukaan pada spesimen menggunakan alat surface roughness tester dengan cara mengukur berulang sebanyak 3 kali hingga mendapatkan 9 data nilai kekasaran aritmatik ( $\mathrm{Ra}$ ) pada tiap spesimen. Berikut adalah skema titik pengukuran spesimen yang ditunjukkan pada gambar 7 .
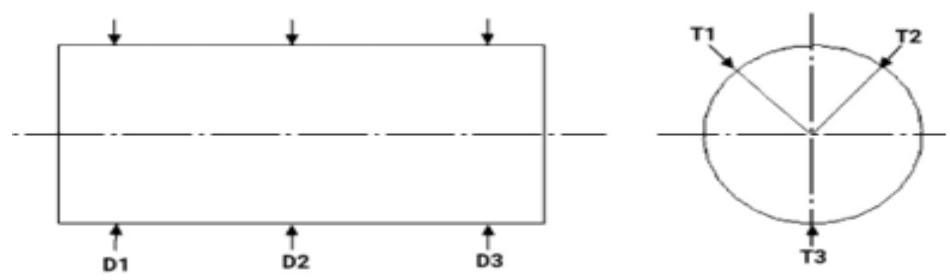

Gambar 7. Skema titik pengukuran spesimen

\section{HASIL DAN PEMBAHASAN}

Pengujian dilakukan untuk mengetahui pengaruh variasi besaran sudut buang dan besaran sudut bebas terhadap kekasaran permukaan baja st 41 . Berikut ini merupakan hasil dari pengujian spesimen menggunakan alat ukur surface roughness tester yang kemudian akan dihitung nilai kekasaran permukaan rata-rata tiap spesimen dapat dilihat pada tabel 2 .

Tabel 2. Data Hasil Pengukuran

\begin{tabular}{|c|c|c|c|c|c|c|c|c|}
\hline \multirow[t]{2}{*}{ No } & \multicolumn{2}{|c|}{ Sudut $\left(^{\circ}\right)$} & \multirow{2}{*}{$\begin{array}{l}\text { Diameter } \\
\text { ukur }\end{array}$} & \multicolumn{3}{|c|}{ Titik Ukur } & \multirow{2}{*}{$\begin{array}{c}\text { Rata-Rata } \\
(\mu \mathrm{m})\end{array}$} & \multirow{2}{*}{$\begin{array}{c}\text { Rata -Rata } \\
\text { Keseluruhan } \\
(\mu \mathrm{m})\end{array}$} \\
\hline & $\alpha$ & $\beta$ & & T1 & $\mathrm{T} 2$ & T3 & & \\
\hline \multirow{3}{*}{1} & \multirow{3}{*}{6} & \multirow{3}{*}{10} & D1 & 2,136 & 2,604 & 2,574 & 2,438 & \multirow{3}{*}{2,555} \\
\hline & & & $\mathrm{D} 2$ & 2,478 & 2,562 & 2,464 & 2,501 & \\
\hline & & & D3 & 2,556 & 2,703 & 2,918 & 2,726 & \\
\hline
\end{tabular}




\begin{tabular}{|c|c|c|c|c|c|c|c|c|}
\hline \multirow{3}{*}{2} & \multirow{3}{*}{6} & \multirow{3}{*}{12} & D1 & 2,839 & 2,951 & 2,804 & 2,865 & \multirow{3}{*}{2,761} \\
\hline & & & D2 & 2,608 & 2,614 & 2,917 & 2,713 & \\
\hline & & & D3 & 2,699 & 2,526 & 2,887 & 2,704 & \\
\hline \multirow{3}{*}{3} & \multirow{3}{*}{6} & \multirow{3}{*}{14} & D1 & 2,987 & 2,910 & 2,841 & 2,913 & \multirow{3}{*}{2,840} \\
\hline & & & D2 & 2,860 & 2,732 & 2,837 & 2,810 & \\
\hline & & & D3 & 2,771 & 2,718 & 2,904 & 2,798 & \\
\hline \multirow{3}{*}{4} & \multirow{3}{*}{7} & \multirow{3}{*}{10} & D1 & 2,947 & 3,107 & 2,993 & 3,016 & \multirow{3}{*}{3,185} \\
\hline & & & $\mathrm{D} 2$ & 3,112 & 3,283 & 3,431 & 3,275 & \\
\hline & & & D3 & 3,123 & 3,260 & 3,406 & 3,263 & \\
\hline \multirow{3}{*}{5} & \multirow{3}{*}{7} & \multirow{3}{*}{12} & D1 & 3,382 & 3,605 & 3,520 & 3,502 & \multirow{3}{*}{3,566} \\
\hline & & & D2 & 3,633 & 3,318 & 3,664 & 3,538 & \\
\hline & & & D3 & 3,397 & 3,626 & 3,954 & 3,659 & \\
\hline \multirow{3}{*}{6} & \multirow{3}{*}{7} & \multirow{3}{*}{14} & D1 & 3,526 & 3,452 & 3,624 & 3,534 & \multirow{3}{*}{3,671} \\
\hline & & & D2 & 3,360 & 3,776 & 3,562 & 3,566 & \\
\hline & & & D3 & 3,814 & 3,917 & 4,011 & 3,914 & \\
\hline \multirow{3}{*}{7} & \multirow{3}{*}{8} & \multirow{3}{*}{10} & D1 & 3,885 & 3,941 & 4,125 & 3,984 & \multirow{3}{*}{4,146} \\
\hline & & & $\mathrm{D} 2$ & 3,999 & 4,147 & 4,371 & 4,172 & \\
\hline & & & D3 & 4,221 & 4,090 & 4,537 & 4,283 & \\
\hline \multirow{3}{*}{8} & \multirow{3}{*}{8} & \multirow{3}{*}{12} & D1 & 4,424 & 4,287 & 4,748 & 4,498 & \multirow{3}{*}{4,629} \\
\hline & & & $\mathrm{D} 2$ & 4,602 & 4,613 & 4,707 & 4,641 & \\
\hline & & & D3 & 4,579 & 4,674 & 4,990 & 4,748 & \\
\hline \multirow{3}{*}{9} & \multirow{3}{*}{8} & \multirow{3}{*}{14} & D1 & 5,039 & 5,304 & 5,414 & 5,252 & \multirow{3}{*}{5,397} \\
\hline & & & $\mathrm{D} 2$ & 5,175 & 5,126 & 5,393 & 5,231 & \\
\hline & & & D3 & 5,704 & 5,593 & 5,826 & 5,708 & \\
\hline
\end{tabular}

Dari tabel 2 diatas, data hasil pengukuran dari 9 spesimen yang sudah diukur menggunakan alat surface roughness tester dapat dituangkan kedalam bentuk grafik dengan nilai kekasaran rata-rata dari tiap variasi besaran sudut bebas $(\alpha)$ dan besaran sudut buang $(\beta)$ terhadap kekasaran permukaan baja st 41 seperti dibawah ini.

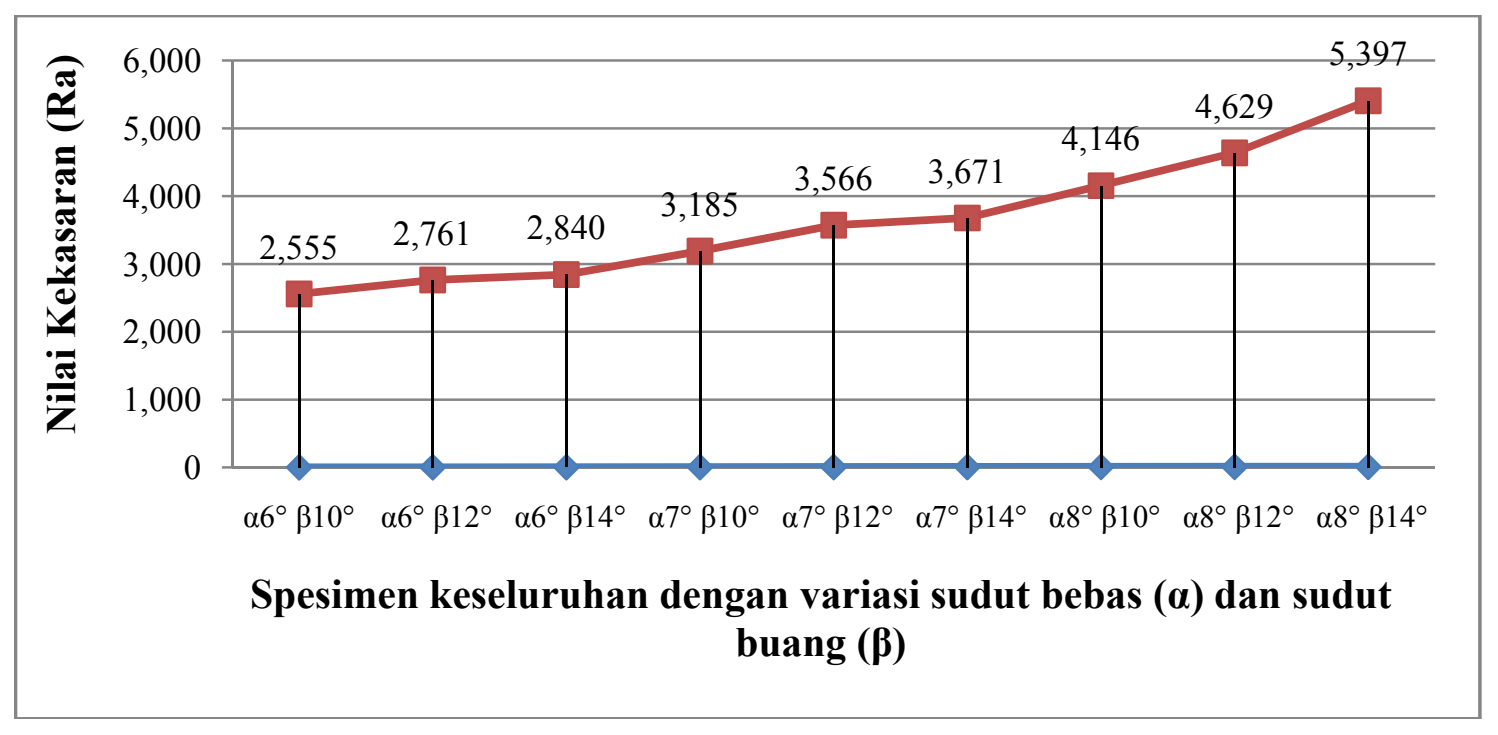

Gambar 8. Grafik hasil pengukuran spesimen keseluruhan

Berdasarkan grafik diatas dapat ditentukan nilai kekasaran yang paling baik (terendah) dari hasil pembubutan spesimen keseluruhan dengan variasi besaran sudut 
bebas $(\alpha) 6^{\circ}, 7^{\circ}, 8^{\circ}$ dan sudut buang $(\beta) 10^{\circ}, 12^{\circ}, 14^{\circ}$. Dapat disimpulkan bahwa nilai kekasaran terendah didapatkan dari hasil pembubutan spesimen dengan besaran sudut bebas $(\alpha) 6^{\circ}$ dan besaran sudut buang $(\beta) 10^{\circ}$ dengan nilai kekasaran permukaan $(\mathrm{Ra})$ sebesar 2,555 $\mu \mathrm{m}$. Sedangkan untuk nilai kekasaran tertinggi dari proses pembubutan dengan besaran sudut bebas $(\alpha) 8^{\circ}$ dan besaran sudut buang $(\beta) 14^{\circ}$ dengan nilai kekasaran permukaan $(\mathrm{Ra})$ sebesar 5,397 $\mu \mathrm{m}$. Jika dilihat dari grafik diatas, terjadi peningkatan nilai kekasaran permukaan yang dipengaruhi oleh variasi besaran sudut bebas $(\alpha)$ dan besaran sudut buang $(\beta)$ yang mana semakin besar sudut bebas $(\alpha)$ dan sudut buang $(\beta)$ maka akan menghasilkan tingkat kekasaran permukaan yang besar (kasar).

\section{KESIMPULAN}

Dari hasil analisa dan pembahasan data, penulis memperoleh kesimpulan yang dapat diambil dari eksperimen mengenai pengaruh variasi besaran sudut buang dan sudut bebas menggunakan pahat tepi rata dengan material pahat HSS terhadap kekasaran permukaan pada proses pembubutan spesimen dengan material spesimen baja St 41 yaitu, hasil dari penelitian ini menunjukkan bahwa pembubutan spesimen dengan besaran sudut bebas $(\alpha) 6^{\circ}$ dan besaran sudut buang $(\beta) 10^{\circ}$ menghasilkan kekasaran permukaan yang paling baik (halus) dibandingkan besaran sudut lainnya dengan nilai kekasaran permukaan (Ra) sebesar 2,555 $\mu \mathrm{m}$. Sedangkan untuk nilai kekasaran tertinggi dari proses pembubutan keseluruhan spesimen yaitu dengan besaran sudut bebas $(\alpha) 8^{\circ}$ dan besaran sudut buang $(\beta) 14^{\circ}$ dengan nilai kekasaran permukaan (Ra) sebesar 5,397 $\mu \mathrm{m}$ dengan menggunakan parameter proses yang sama pada keseluruhan spesimen yaitu kecepatan spindel $280 \mathrm{rpm}$, kedalaman pemotongan $0,8 \mathrm{~mm}$, feeding 0,040 mm/put dan menggunakan alat ukur surface roughness tester. Pada penelitian ini, nilai kekasaran terendah (halus) dipengaruhi oleh variasi besaran sudut bebas $(\alpha)$ dan besaran sudut buang $(\beta)$ terkecil. Sedangkan nilai kekasaran tertinggi (kasar) dipengaruhi oleh variasi besaran sudut bebas $(\alpha)$ dan besaran sudut buang $(\beta)$ terbesar.

\section{DAFTAR PUSTAKA}

[1]. Firstamarsyah, A., \& Sakti, A. (2019). Analisa Merk Pahat dan Sudut Potong Pahat Yang Berbeda Pada Mesin Bubut Konvensional Dalam Proses Bubut Rata Terhadap Tingkat Kekasaran Permukaan Benda Kerja St 41. JPTM. Volume 08 Nomor 03, Hal. 31-36.

[2]. Hendrawan, A. (2015). Pengaruh Jenis Pahat Terhadap Kekerasan Permukaan Pada Saat Pembubutan Baja St 41. Jurnal Nozzle Volume 5 Nomor 2, Hal. 147-149.

[3]. Paridawati. (2015). Pengaruh Kecepatan dan Sudut Potong Terhadap Kekasaran Benda Kerja Pada Mesin Bubut. Jurnal Imiah Teknik Mesin, Vol. 3, Hal. 53-67.

[4]. Pramawata, P. (2013). Pengaruh Jenis Pahat, Sudut Pahat, Dan Kedalaman Pemakanan Terhadap Tingkat Kekasaran Dan Kekerasan Pada Proses Bubut Rata Baja St 42. JTM. Volume 01 Nomor 03, Hal. 56-64.

[5]. Priyadi, S. (2017). Pengaruh Sudut Pahat Pada Proses Bubut Rata Terhadap Tingkat Kekasaran Permukaan Benda Kerja. Semarang: lib.unnes.ac.id. 
[6]. Raul, Widiyanti, \& Poppy. (2016). Pengaruh Variasi Kecepatan Potong Dan Kedalaman Potong Pada Mesin Bubut Terhadap Tingkat Kekasaran Permukaan Benda Kerja St 41. Jurnal Teknik Mesin, Tahun 24, No. 1, Hal. 1-9.

[7]. Sumbodo, W. (2008). Teknik Produksi Mesin Industri Jilid 2. Jakarta: Direktorat Pembinaan Sekolah Menengah Kejuruan.

[8]. Susarno, A. (2012). Studi Pengaruh Sudut Potong Pahat Hss Pada Proses Bubut Dengan Tipe Orthogonal Terhadap Kekasaran Permukaan. Surakarta: eprints.ums.ac.id. 